\title{
Editorial
}

\section{Editorial: Why We Need to Humanize Online Education}

\author{
Betül C. Czerkawski \\ Editor, ITET
}

\author{
Nicole Schmidt \\ Managing Editor, ITET
}

\begin{abstract}
While much of the current discourse focuses on interaction, active participation, motivation, and student engagement in online learning, less attention is paid to the challenge of humanizing distance education. Although the human element is undoubtedly inherent to each of these concerns, it often takes a peripheral role in pedagogical discussions. The following editorial considers how teachers can personalize their courses and how they can facilitate the development of an online community of peers. The editorial concludes with an open call for papers exploring this line of thinking
\end{abstract}

Keywords: online learning; engagement; personalization; humanization

When it comes to online education, most discussions revolve around interaction, active participation, motivation, and student engagement in virtual teaching and learning activities. Online instructors share methods of adapting instructional strategies and techniques in their course design and development to involve students in meaningful online learning experiences. However, this conversation tends to overlook a core phenomenon that underscores the success of such strategies and techniques: the delivery of the "human" element to digital instruction.

More specifically, a seldom discussed issue is how to humanize students' learning experiences so they will relate to their instructors and peers in the duration of 15-16 week semesters. Clark and Mayer (2011) call this the 'personalization' principle, where online instructors use a conversational and polite tone and implement a friendly voice into the course materials so that students have meaningful experiences that lead to better learning gains. Clark and Mayer (2011) also argue that including spoken and printed text in online courses, where instructors use a conversational tone, greatly helps students to "prime appropriate information processing" (p.184).

Using multimedia videos in which instructors adopt a friendly and polite tone to lecture and provide appropriate personal examples for learners goes a long way toward meeting the goal of humanizing online learning. Smartly designed intelligent agents can also lead 
to more meaningful experiences for the students. Although students take online courses primarily to learn, the information doesn't have to be presented in a formal, passive, and impersonal manner. Students respond to the friendly tone of the instructor positively because they see a conversation partner (in this case, the instructor) to whom they are more enthusiastic to respond. This technique, in turn, inspires them to engage with the content in a way that formal text or multimedia-based techniques do not typically achieve.

Often, simply showing up is crucial for student learning, especially in fully asynchronous courses. Teacher presence is described by Anderson, Rourke, Garrison, and Archer (2001) as development and supervision of cognitive and social processes, directed toward learning outcomes that are meaningful to the student on both personal and educational levels. Teaching presence is usually seen as the moderation of online discourses, but it goes beyond the online discussion forums by including all types of feedback students receive from their instructor, explicitly or implicitly. All activities performed by the instructor prior to and during the online course can become increasingly effective if students feel the presence of their teacher in teaching and learning documents as well as activities. Anderson et al. (2001) consider teaching presence in online courses as the main binding element that cultivates a learning community among the students and instructor. It is this learning community where students feel connected to their peers and also to their instructor.

Even without constant teacher presence, a sense of community between peers can develop through careful planning and experimentation in an online course. Various methods, including social media (Dunlap \& Lowenthal, 2009), asynchronous audio instructor feedback (Ice, Curis, Phillips, \& Wells, 2007), and asynchronous video (Broup, West, \& Graham, 2011) have been suggested as means of uniting students within a course. However, new tricks and tools are constantly emerging within the field of Educational Technology.

As more and more online courses are offered in higher education every year and further efforts are taken to invest in the quality of online education, there is a need to stay upto-date on best practices and innovations. We look forward to receiving more research papers exploring instructional design strategies as well as technologies that will help humanize both student and instructor experiences in online courses. In the end, learning, especially online learning, is not only a solitary cognitive activity but also one with social connotations in web-based environments. 


\section{References}

Anderson, T., Rourke, L., Garrison, D. \& Archer, W., (2001). Assessing teaching presence in a computer conferencing context. Journal of Asynchronous Learning Networks, 5 (2), 1-17.

Borup, J., West, R. E., \& Graham, C. R. (2012). Improving online social presence through asynchronous video. The Internet and Higher Education, 15(3), 195-203.

Clark, R. C., \& Mayer, R. E. (2011). E-learning and the science of instruction: Proven guidelines for consumers and designers of multimedia learning. San Francisco, CA: Pfeiffer.

Dunlap, J. C., \& Lowenthal, P. R. (2009). Tweeting the night away: Using Twitter to enhance social presence. Journal of Information Systems Education, 20(2), 129.

Ice, P., Curtis, R., Phillips, P., \& Wells, J. (2007). Using asynchronous audio feedback to enhance teaching presence and students' sense of community. Journal of Asynchronous Learning Networks, 11(2), 3-25. 